\title{
A competitividade nos Clusters da indústria de borracha do sudeste asiático
}

\author{
Luís Gustavo Mazzaro \\ Fábio Lotti Oliva ${ }^{2}$ \\ Celso Cláudio de Hildebrand e Grisi ${ }^{3}$ \\ Hubert Drouvot \\ Sérgio Crispim ${ }^{5}$ \\ Marcos Antonio Gaspar ${ }^{6}$
}

\section{Resumo}

O objetivo deste trabalho é estudar a competitividade do setor manufatureiro de produtos de borracha da Malásia, através da análise da indústria de luvas médicas. A articulação entre o setor produtivo e o Estado privilegiou a atração de investimentos estrangeiros, o foco nas exportações, a busca da competitividade através da produtividade e da melhor utilização dos recursos. Essas práticas são coerentes com a Teoria dos Aglomerados, pois enfatizam justamente o crescimento sustentado da produtividade e da competitividade, e não a concessão de vantagens temporárias ou concentração empresarial. Tem sido expressiva a atuação das instituições especializadas de pesquisa tecnológica e das associações dos fabricantes para fins de normatização, melhora da qualidade e promoção do produto no exterior. $\mathrm{O}$ caso pode servir de contraponto para avaliação das estratégias para o desenvolvimento industrial no Brasil.

Palavras-chave: Clusters. Competitividade. Indústria da borracha.

\footnotetext{
1Pós-Graduação pela Fundação Instituto de Administração. Professor da Fundação Instituto de Administração. Endereço: Av. Prof. Luciano Gualberto, 908 - Cidade Universitária - sala C-27. E-mail: luismazzaro@ig.com.br.

${ }^{2}$ Doutor pela Universidade de São Paulo. Professor da Fundação Instituto de Administração e Universidade de São Paulo. Endereço: Av. Prof. Luciano Gualberto, 908 - Cidade Universitária - sala C-27. E-mail: fabiousp@usp.br.

${ }^{3}$ Titular pela Universidade de São Paulo. Professor da Universidade de São Paulo. Endereço: Av. Prof. Luciano Gualberto, 908 - Cidade Universitária -sala G-105. E-mail: cchgfea1@usp.br

${ }^{4}$ Doutor em Sciences de Gestion. pela Université Pierre Mendès France de Grenoble, UPMF/CERAG, França. Mestre de Conferência. Université Pierre Mendès France - I.A.E. de Grenoble. Endereço: Université Pierre-Mendes-France/BP 46/38040, Grenoble Cedex 9. E-mail: hubert.drouvot@iaegrenoble.fr.

${ }^{5}$ Livre Docente em Gestão de Marketing pela Universidade de São Paulo. Professor da Universidade Municipal de São Caetano e Universidade de São Paulo. Endereço: Rua Santo Antonio, 50 - São Caetano do Sul (SP) - CEP: 09521-160.E-mail: scrispim@uol.com.br

${ }^{6}$ Doutor em Administração pela Faculdade de Economia, Administração e Contabilidade da Universidade de São Paulo - FEA/USP. Endereço: Universidade Municipal de São Caetano. Rua Santo Antonio, 50 - São Caetano do Sul (SP) - CEP: 09521-160. E-mail: marcos.gaspar@uscs.edu.br. Artigo recebido em: 14/07/2008. Aceito em: 13/12/2008. Membro do Corpo Editorial Científico responsável pelo processo editorial: Thomas G. Brashear.
} 


\section{Introdução}

O consumo de luvas médico-hospitalares cresceu dramaticamente desde meados dos anos 80, principalmente devido à epidemia mundial de AIDS. Concomitantemente, o eixo de produção e inovação tecnológica desses artigos concentrou-se no Sudeste Asiático, notadamente na Malásia - país chave para este estudo. A Malásia responde por aproximadamente $60 \%$ da produção mundial de luvas médicas. A principal matéria prima para as luvas é o látex natural, extraído da seringueira (Hevea brasiliensis). Esse país é o terceiro maior produtor dessa commodity. A simples vantagem comparativa de custo de aquisição de matéria prima não parece explicar a liderança do setor manufatureiro malaio. Sabe-se que esse pequeno país do sudeste asiático tem destacada competitividade global. Segundo o Anuário de Competitividade Mundial - 2004, do Instituto de Desenvolvimento Gerencial, de Lausanne - Suíça, a Malásia figura na 16a posição geral e como o quinto país mais competitivo entre os de população acima de 20 milhões de habitantes. Esta performance suplanta as do Japão, China, Tailândia e Coréia do Sul. Já o Brasil ocupa a modesta 53a colocação, enquanto que o estado de São Paulo, a 47a (IMD, 2004).

Algumas questóes nortearam a pesquisa: Como a indústria de luvas de látex insere-se nesse contexto? Que conjunto de estratégias conduziu uma ex-colônia agrícola dos anos 50 a transformar-se em exportador de produtos de valor agregado, de maquinário especializado e de tecnologia? Quais outros fatores estiveram presentes nesse notável desenvolvimento?

O presente trabalho busca estudar o desenvolvimento da competitividade do setor de luvas médico-hospitalares na Malásia, através da análise dos fatores de produção, da demanda, de setores correlatos e de apoio, e da estratégia e rivalidade das empresas, segundo a Teoria de Aglomerados.

\section{Base Conceitual}

\subsection{Competitividade Nacional}

Os condicionantes da competitividade nacional são amplamente descritos e analisados por Porter (1990), em sua obra A Vantagem Competitiva 
das Nações. Através da investigação dos Padrões do Êxito Competitivo dos Países, pesquisou-se os motivos pelos quais os países ganham vantagem competitiva em determinados setores e suas implicações para a estratégia das empresas e para as economias nacionais. Os países selecionados foram: Dinamarca, Alemanha, Itália, Japão, Coreia, Cingapura, Suécia, Suíça, Reino Unido e EUA, que representavam em 1985 mais de 50\% das exportações mundiais.

A principal conclusão do estudo é que a competitividade não é condicionada, conforme o pensamento dominante, pelos fatores clássicos de produção, como mão de obra e matérias-primas, ou por variáveis macroeconômicas, como taxa de juros, taxa de câmbio, carga tributária e déficit público, nem pela intervenção governamental, como subsídios, políticas de concentração ou protecionismo, e nem sequer por meras diferenças de práticas gerenciais: "O único conceito significativo de competitividade nacional é a produtividade" (PORTER, 1999, p. 172). O estudo incluiu mais de 100 setores e grupos de setores. Para compreender a competitividade nacional, há que se estudar minuciosamente os diversos segmentos da economia nos determinantes da produtividade e da sua taxa de crescimento. Faz-se necessária uma nova teoria que suplante a das vantagens comparativas tradicionais, que forneça uma ferramenta de análise do sistema ou conjunto dinâmico de fatores que formam o ambiente empresarial de um país ou localidade, e que explique por que certas empresas promovem inovações constantes, buscam a melhoria contínua e formas mais sofisticadas de vantagem competitiva, superam barreiras à mudança e à inovação. A análise de quatro atributos de um país, que formam o chamado Diamante da Vantagem Nacional, constitui essa ferramenta de análise dessa nova teoria. Os atributos são:

a) Condições dos fatores de produção. A posição do país quanto aos fatores de produção, como mão de obra qualificada e infraestrutura, necessários para competir num determinado setor.

b) Condições da demanda. A natureza da demanda no mercado interno para os produtos ou serviços do setor.

c) Setores correlatos e de apoio. A presença ou a ausência, no país, de setores fornecedores e outros correlatos que sejam internacionalmente competitivos.

d) Estratégia, estrutura e rivalidade das empresas. As condições predominantes no país, que determinam como as empresas são constituídas, organizadas e gerenciadas, assim como a rivalidade no 
mercado interno (PORTER, 1999, p. 178). Há dois pontos em especial no Diamante que fornecem sinergia ao sistema se ocorrem juntos e de forma acentuada: a rivalidade doméstica e a concentração geográfica.

\subsection{Discussão Sobre o Conceito de Clusters}

A relação entre concentração geográfica e competitividade das empresas foi pioneiramente tratada por Marshall. O modelo de análise de Marshall resumia a questão a uma tríade de economias externas: disponibilidade local de mão de obra especializada, apoio local e tradições históricas, divisão do trabalho entre as firmas da localidade, que concorriam para criar a atmosfera industrial local (MARTIN; SUNLEY, 2001). O modelo não se aprofundava na dinâmica dos distritos industriais. Quase um século depois, na esteira dos estudos sobre competitividade das nações, o papel das localidades retorna ao centro do debate sobre competição internacional. Os aglomerados, clusters no original, são agrupamentos geográficos de empresas, fornecedores, setores relacionados e instituições especializadas existentes em determinada área de um país, estado ou cidade.

Os aglomerados são uma constante nas nações mais desenvolvidas e nos seus setores mais competitivos. Oferecem uma nova abordagem de desenvolvimento econômico. Os aglomerados são a antítese da ideia errônea de que a globalização, uma vez que permite às empresas acessarem capital, bens e tecnologia em qualquer parte do mundo, tornou a questão da localização menos importante. Diferentemente do enfoque tradicional de agrupamentos de empresas, os aglomerados, conceito mais amplo que o de setores, captam outros elos que seriam menos perceptíveis para a competitividade, mas que lhe são críticos, como complementaridades e extravasamentos em termos de tecnologia, qualificação, informação, marketing e necessidades dos clientes que vão além das empresas e setores. Os aglomerados são uma faceta do Diamante: setores correlatos e de apoio. As análises que abordam os aglomerados apenas pelo prisma da proximidade com fontes de matéria-prima e mercados estão ultrapassadas na nova economia. Essas explicações ficaram comprometidas pelas facilidades de acesso inerentes à globalização (PORTER, 1999). 
No Brasil, o conceito de clusters foi recentemente reconhecido e incorporado pelo Governo Federal na Política de Desenvolvimento Econômico, através da Secretaria de Desenvolvimento da Produção (SDP), ligada ao Ministério do Desenvolvimento, Indústria e Comércio Exterior (MDIC). O Governo Federal está organizando o tema Arranjos Produtivos Locais (APL) - denominação adotada pelo BNDES - Banco Nacional de Desenvolvimento Econômico e Social - para aglomerados. Instituiu um Grupo de Trabalho para atuar em 11 APLs pilotos, distribuídos nas cinco regiões do país, com o propósito de testar a metodologia de ação integrada (website do MDCI, Governo do Brasil - 2005). Embora Porter influencie na definição de políticas de governos e empresas em todos os níveis, estudos semelhantes de outros autores, notadamente de geógrafos, não tem conquistado a mesma visibilidade. $\mathrm{O}$ fato de tal autor estar associado ao estudo da competitividade nas últimas duas décadas pode explicar o sucesso na aceitação das suas ideias. Entretanto, ainda segundo Martin e Sunley (2001), duas limitações principais devem ser consideradas: um conceito tão abrangente do que é um aglomerado não pode prover um modelo universal e determinístico relacionando aglomeração e desenvolvimento regional e, como decorrência, simplesmente por que há uma associação entre desenvolvimento acelerado de algumas indústrias e várias formas de concentração geográfica, não significa que esta concentração é a causa principal do sucesso dessas empresas.

\subsection{A Produtividade nos Aglomerados}

A Produtividade, nos dias atuais, permeia todo o estudo, e é uma das mais importantes armas, da competição. Ela é medida em três níveis: operação, empresa e nação. No nível da operação, produtividade é a relação entre a quantidade produzida e os recursos a ela aplicados; no da empresa, é a relação entre o faturamento e os custos totais; e no nível da nação, é a relação entre o Produto Nacional Bruto e a população (CONTADOR, 1995, p. 51).

Há certas características presentes nos aglomerados que influenciam positivamente a produtividade e, mais importante, o crescimento da produtividade (PORTER, 1999): acesso a insumos, a pessoal especializado e à informação, complementaridades entre as atividades dos diversos participantes, acesso a instituições e a bens públicos e incentivos à mensuração do desempenho (benchmarking). 


\subsection{O Papel dos Governos nos Aglomerados}

Porter (1999) argumenta que o governo não tem capacidade de criar setores competitivos; são as empresas que têm esse papel. O governo tem atuação parcial, que é favorável apenas quando age em conjunto com outras condições positivas do Diamante. Ao governo caberia: incentivar, impelir e desafiar as empresas no desenvolvimento do seu potencial competitivo; focar a criação de fatores especializados, como centros de pesquisas, capacitação tecnológica e aprendizado especializado; evitar intervenção no mercado; aplicar normas rigorosas sobre produtos, segurança e meio ambiente; restringir ao máximo a cooperação entre setores rivais e aplicar políticas internas vigorosas na defesa da concorrência; e promover objetivos que conduzam a investimentos sustentados.

Erro comum das políticas industriais é o de proporcionar vantagens de custo estáticas e de curto prazo, que tendem a solapar a iniciativa empresarial de inovação. A tendência dos governos experimentarem políticas como a administração da taxa de câmbio, medidas controladoras do comércio, atenuação de medidas de defesa da concorrência, geralmente têm sido contraproducentes. As ações do Estado, em muitos casos, são conduzidas em vista do curto prazo, enquanto que o desenvolvimento das potencialidades competitivas requer planejamento de longo prazo e, muitas vezes, medidas que geram transtornos imediatos e cujos resultados serão percebidos somente em gerações.

No âmbito interno dos aglomerados, o Estado deveria favorecer o desenvolvimento de fatores avançados e especializados, política de ciência e tecnologia, atração de investimentos externos, reforma de regulamentos, promoção de exportações, levantamento e disseminação de informações econômicas.

\section{Aspectos Metodológicos}

Conforme Yin (2003, p. 19), "o estudo de caso é a estratégia preferida quando se colocam questões do tipo 'como' e "por que', focando fenômenos contemporâneos reais e sobre cujos acontecimentos o pesquisador tem pouco ou nenhum controle. As fontes de evidências e dados para a condução do estudo são as publicações estatísticas, técnicas e econômicas setoriais e de negócios, disponíveis em manuais, livros, jornais e em websites oficiais da Malásia, das associações de produtores, exportadores e das instituições 
de apoio e pesquisa. Há também estudos anteriores tratando do desenvolvimento econômico local.

Como pressupostos básicos, tem-se que:

P1) O setor de luvas médicas da Malásia é um aglomerado;

P2) Os aglomerados possuem dinâmica benéfica para o crescimento da produtividade; $e$

P3) A produtividade do setor é o maior condicionante de sua competitividade.

A partir da revisão teórica, sabe-se que há quatro fatores que determinam a competitividade da localidade em um setor: 1) Condição dos fatores de produção; 2) Condições da demanda; 3) Setores correlatos e de apoio; e 4) Estratégia, estrutura e rivalidade das empresas. Ainda dentro deste modelo conceitual, identifica-se que o setor manufatureiro de artefatos de borracha da Malásia é um aglomerado produtivo, e que daí decorrem uma série de vantagens competitivas.

Retomando a questão da produtividade como fator chave e de que os aglomerados têm implicações positivas no fator de setores correlatos e de apoio, procura-se desvendar como as características pertinentes aos aglomerados influenciam a produtividade e competitividade. É necessário partir de uma análise abrangente - do País - para depois abordar o aglomerado. Para apresentação e análise dos dados, adota-se o roteiro de tópicos baseado no proposto por Sölvell, Lindqvist, Ketels (2003), fracionando e encadeando os fatores na seguinte estrutura: a) Performance Econômica Geral (escolhas políticas macro e microeconômicas); b) Ambiente Geral de Negócios; c) Análise Interna do Aglomerado (Evolução do Aglomerado, O Aglomerado Hoje, Os Quatro Fatores de Competitividade no Aglomerado); e d) Identificação das Questões Estratégicas: Qualidade e Produtividade no Aglomerado.

\section{Análise dos Resultados}

\subsection{Malásia: um Retrospecto do Histórico Político-Econômico}

Localizada entre o Estreito de Málaca e o Sul do Mar da China, a Malásia é um país jovem. Até o final do Século XIX era apenas uma coleção de 
sultanatos independentes, que dividiam a península, e de entrepostos comerciais coloniais. Esses diferentes Estados foram agrupados pelos britânicos em uma federação, cuja independência foi concedida apenas em 1957. Cingapura deixou a federação em 1965, basicamente por incompatibilidades religiosas e culturais.

A Malásia é um dos líderes da Associação de Nações do Sudeste Asiático (ASEAN). Desde a independência, sua economia tem sofrido alterações radicais. $\mathrm{O}$ primeiro plano nacional de desenvolvimento focou a expansão agrícola e a redução da dependência da monocultura da seringueira. Posteriormente, notadamente a partir dos anos 80, a manufatura passou a ser priorizada, tendo ultrapassado, em 1987, a contribuição do setor agrícola para o Produto Interno Bruto (PIB). O setor de serviços cresceu ainda mais rapidamente no período. As políticas econômicas e sociais, implementadas através do New Economic Policy (NEP, 1970) e New Development Policy (NDP, 1991) visaram diminuir desigualdades econômicas entre as diversas etnias que compõe o país. Historicamente, os malaios de origem chinesa dominam o comércio e a indústria locais. Assim, o NEP buscou melhorar o equilíbrio social e diminuir as tensões entre grupos. O NPD, socialmente mais liberal, promoveu a implantação de indústrias de alta tecnologia, incentivou a produção de maior valor agregado, a capacitação de mão de obra e o crescimento da produtividade. É a base da estratégia de desenvolvimento econômico do governo.

A visão lançada em 1991 pelo ex-primeiro-ministro, Dr. Mahathir Mohamad, é a Malásia elevar-se ao status de país desenvolvido em 2020, aproximando as etnias e investindo em setores da economia onde o diferencial não esteja no baixo custo de mão de obra, mas em altos níveis de educação e capacitação. Esse movimento tem seu marco em Cyberjaya, um supercorredor multimídia, o Silicon Valley oriental, ao sul da capital Kuala Lumpur, com investimento de 20 bilhões de dólares (ELIOT; BICKERSETH, 2002).

\subsection{Performance Econômica Geral e Ambiente de Negócios}

Em termos macroeconômicos, o país tem apresentado quadro de crescimento sustentado a boas taxas, aumento da produtividade global, baixo desemprego, baixa inflação, câmbio fixo, déficit fiscal baixo e dívida pública estável. Quanto à performance microeconômica destaca-se o comércio exterior, que equivale a duas vezes o PIB e ostenta um superávit de US\$21,3 
bilhões em 2004. Os investimentos externos diretos totalizaram US\$3,45 bilhões em 2004. Alemanha, Japão, Cingapura, EUA e Canadá concentraram $75 \%$ destes aportes, distribuídos em 295 projetos (MITI - Industry, Investment, Trade and Productivity Performance - 2004).

No quesito educação, em 2003, 98,5\% das crianças estava nas escolas, e a população universitária ultrapassava 290 mil jovens. Some-se a isso o fato de que a língua inglesa é o segundo idioma para maioria da população que vive nos grandes centros. $\mathrm{O}$ ambiente geral de negócios da Malásia caracteriza-se pela estabilidade política e social, governo que incentiva e recompensa os investimentos externos, sistema de transporte e outras infraestruturas públicas bem estabelecidas, sistema Judicial moderno - fruto da herança colonial Britânica -, força de trabalho capacitada, caracterizada pela habilidade manual, e alto senso de responsabilidade.

Assim, o setor de luvas médicas insere-se em um ambiente geralmente atrativo para investimentos, inclusive de empresas multinacionais, que encontram, em larga escala, funcionários qualificados e com domínio da língua inglesa.

\subsection{Política Industrial}

O Governo da Malásia estabeleceu, desde 1986, políticas específicas para promover o desenvolvimento industrial: o Plano Mestre Industrial (Industrial Master Plan - IMP1 - 1986/1995) e o Segundo Plano Mestre Industrial (Second Industrial Master Plan - IMP2 - 1996/2005).

O IMP1 constituiu um dos instrumentos para o cumprimento das metas do NEP (1971/1991). Visou otimizar a utilização dos recursos naturais através de atividades de fabricação de produtos com maior valor agregado. Focouse no desenvolvimento da indústria de produtos de borracha e de outros 11 setores produtivos específicos, baseados ou não em recursos naturais, com as seguintes estratégias: a) Industrialização visando o mercado externo e crescimento das exportações; b) Desenvolvimento intenso das indústrias baseadas em recursos naturais; c) Diversificação e melhoria das indústrias exportadoras não baseadas em recursos naturais; e d) Desenvolvimento de tecnologia e da mão de obra, aperfeiçoamento do sistema de incentivos, desenvolvimento de infraestrutura, modernização e racionalização do setor para apoiar a estratégia de industrialização voltada para exportação. 
As recomendações chave do IMP1 foram implementadas, inclusive a consolidação de incentivos fiscais para novos investimentos, integração das cadeias produtivas, exportação e treinamento. A Lei de Promoção a Investimentos, de 1986, e as modificações na Legislação de Imposto de Renda atraíram investidores. Houve liberalização de políticas, procedimentos e gargalos que afetavam o setor produtivo.

Os principais resultados no período superaram as metas iniciais: a) $\mathrm{O}$ nível de emprego no setor de transformação cresceu à taxa média de 8,9\% a.a.; b) Em 1995, o setor empregava 2,05 milhões de trabalhadores, correspondendo a 25,9\% dos empregos do país; c) A participação de produtos manufaturados na pauta de exportações cresceu de 33\%, em 1985, para $79,8 \%$, em 1995.

O lançamento do IMP2 significou uma nova era industrial para a Malásia, baseando-se em cinco estratégias: a) Orientação global. Aprofundamento da orientação anterior, puramente para exportação, para uma orientação global. Desenvolvimento de marketing internacional, de empresas com qualidade e escalas mundiais; b) Realce para competitividade. Desenvolvimento dos aglomerados, com o aprofundamento e alargamento da integração industrial e ênfase na produtividade; c) Melhora da base econômica. Capacitação e administração de recursos humanos, aquisição e capacidade de absorção de tecnologia. Melhora da infraestrutura física, dos procedimentos administrativos de apoio, incentivos fiscais e não fiscais e serviços de apoio aos negócios; d) Aumento de participação de empresas controladas por empresários locais. Isso se deu em vários segmentos, mas especialmente nos aglomerados estratégicos para o desenvolvimento industrial; e) Processos conduzidos pelo conhecimento e informação intensiva. Utilização de conhecimento $e$ informação intensiva na manufatura e em atividades relacionadas, tais como Pesquisa e Desenvolvimento (P\&D), projeto de produto, marketing, distribuição e aquisição. Ampliação do uso de Tecnologia da Informação (TI) e E-commerce.

Partindo desta visão estratégica de desenvolvimento integrado da indústria, o IMP2 tem duas linhas de ação:

1) Orientação para manufatura ++ (Manufacturing Plus-Plus Orientation) - O IMP2 busca uma visão integrada que abrange serviços de sustentação da manufatura e do negócio. Orienta as companhias que já operam na Malásia, bem como as entrantes, a in- 
vestir em $\mathrm{P} \& \mathrm{D}$, projeto de produto, distribuição, logística e marketing. Essas indústrias são incentivadas a aumentar sua eficiência com maior automatização, desenvolvimento tecnológico e de habilidades que promovam melhoria gerencial. Enfatiza a integração da cadeia de valor, a fim de fortalecer os laços industriais e aumentar a produtividade e a competitividade.

2) Desenvolvimento Industrial Baseado em Aglomerados - Três grandes grupos de aglomerados industriais foram identificados: a) Conglomerados multinacionais, dirigidos ao mercado global, tais como eletroeletrônicos e as indústrias têxteis; b) Aglomerados baseados em recursos naturais: madeira, borracha, petroquímica e óleo de palma; c) Aglomerados tecnológicos: indústrias automotiva e aeroespacial.

Foram criados 21 grupos de trabalho para aglomerados e cinco forças tarefa para executar os planos de ação esboçados no IMP2, identificar estratégias e falhas na implementação, $e$ tomar as medidas necessárias para o crescimento da competitividade do setor de manufatura. $\mathrm{O}$ investimento total necessário foi estimado em US\$ 66 bilhões para o período.

Esses grupos de trabalho e forças tarefa envolviam os setores público e privado no aperfeiçoamento da competitividade dos aglomerados, através da integração das indústrias principais, fornecedores, indústrias de apoio, serviços críticos de apoio a negócios, infraestrutura necessária e instituições de pesquisa.

Assim como no IMP1, o setor manufatureiro de borracha foi incluído entre os dez grupos escolhidos para implementação dessa política.

\subsection{A Indústria da Borracha na Malásia}

A Malásia é o décimo maior consumidor de toda borracha produzida mundialmente, compreendendo borracha natural, sintética e látices. É o quinto maior consumidor de borracha natural e o primeiro de látex natural concentrado (Tabela 1). É líder no fornecimento de luvas médicas, de cateteres e de fios e cordões de látex. Ocupa a terceira colocação entre os maiores produtores e exportadores de borracha (MREPC, 2005). 
Os fabricantes desses artigos são empresas multinacionais dos EUA, Europa e Japão, e pequenas e médias empresas locais. Essa indústria é capaz de fornecer uma variedade de 40.000 produtos diferentes. Os itens selecionados da pauta de exportações, na ordem de participação no volume de vendas, são: luvas (outras que não cirúrgicas), cateteres, luvas cirúrgicas, fios e cordões vulcanizados, tubos e conexões para a indústria, preservativos, banda de borracha pré-vulcanizada, tecidos emborrachados, correias, balões de ar, fios de cabos elétricos, dedeiras, bicos de mamadeira, chupetas e anéis de vedação (MREPC, 2005). O consumo de borracha pela indústria da Malásia está estratificado conforme tabela a seguir:

Tabela 1: Consumo Doméstico da Indústria de Borracha na Malásia (em toneladas).

\begin{tabular}{|c|c|c|c|c|c|c|c|c|c|c|c|}
\hline \multirow[b]{3}{*}{ 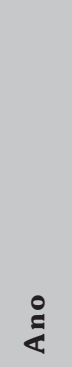 } & \multirow[b]{3}{*}{ 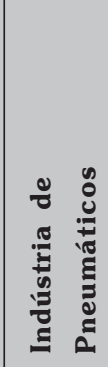 } & \multirow[b]{3}{*}{$\begin{array}{l}\frac{0}{0} \\
\frac{\pi}{\pi} \\
\frac{0}{\pi} \\
\text { Uj }\end{array}$} & \multicolumn{7}{|c|}{ Produtos Diversos de Borracha } & \multirow{3}{*}{ 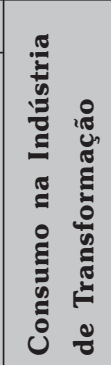 } & \multirow[b]{3}{*}{ } \\
\hline & & & \multirow[b]{2}{*}{ 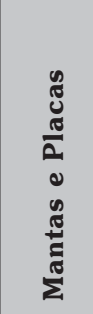 } & \multicolumn{5}{|c|}{ Produtos de Látex } & \multirow[b]{2}{*}{ 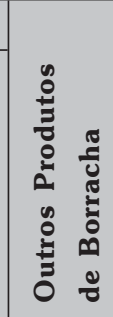 } & & \\
\hline & & & & 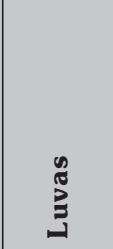 & $\stackrel{0}{\stackrel{0}{2}}$ & 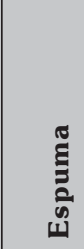 & 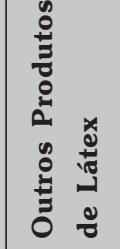 & 章 & & & \\
\hline 2000 & 55,116 & 3,317 & 20,746 & 201,159 & 64,189 & 3,253 & 4,880 & 273,481 & 6,571 & 4,484 & 363,715 \\
\hline 2001 & 60,536 & 3,272 & 19,224 & 224,430 & 72,099 & 4,219 & 5,010 & 305,758 & 7,520 & 4,578 & 400,888 \\
\hline 2002 & 60,229 & 3,686 & 19,572 & 224,644 & 78,049 & 5,255 & 5,340 & \begin{tabular}{|l|}
313,288 \\
\end{tabular} & 7,091 & 4,017 & 407,883 \\
\hline 2003 & 76,148 & 2,545 & 18,992 & 216,589 & 85,711 & 4,770 & 4,919 & 311,989 & 7,580 & 3,522 & 420,776 \\
\hline
\end{tabular}

Fonte: Estatísticas Mensais da Borracha, Departamento de Estatística, Governo da Malásia (2005).

Entre os diversos artefatos produzidos com látex natural, as luvas em geral têm participação preponderante: $72 \%$ no período estudado (2000/ 2004). Assim como, em comparação com o total de borracha consumida, representa cerca de $54 \%$ do total processado. 


\subsection{O Aglomerado de Luvas Médicas}

A Malaysian Rubber Gloves Manufactures Association (MARGMA, 2005) classifica as luvas de látex nas seguintes categorias: a) Luvas para salas limpas; b) Luvas de exame, usadas principalmente em instalações médico-hospitalares e consultórios dentais, mas também na indústria alimentícia e cozinhas, cabeleireiros e jardinagem; c) Luvas para uso doméstico; e) Luvas para uso de indústria; e f) Luvas cirúrgicas.

Em 2001, o mercado mundial de luvas médicas movimentou cerca de US $\$ 1,2$ bilhões, totalizando 40 bilhões de pares. A Malásia teve participação estimada em $60 \%$ no volume. Outros países exportadores são Tailândia, Indonésia, China, Sri Lanka e Índia (MALAYSIA RUBBER INDUSTRY GLOVES EXPORTERS, Industry New, 2004). Dados mais recentes, apresentados na tabela anterior, indicam que a produção de luvas médicas na Malásia continua expandindo-se.

O embrião do aglomerado de luvas médicas foi o setor primário, os seringais, em resumo. A produção de borracha e látex natural é considerada estratégica pela Malásia. A Malásia foi até 1993 o maior produtor mundial de látex natural. Entre os fatores que conduziram a esta liderança destaca-se o investimento realizado ao longo de décadas na pesquisa e desenvolvimento da tecnologia da borracha natural. Através do Rubber Research Institute of Malaysia (RRIM), desenvolveram-se clones de seringueira cada vez mais produtivos e resistentes às pragas, otimizaram-se os métodos de cultivo da seringueira e de extração do látex, e criaram-se normas e padronização que passaram a ser adotadas internacionalmente. A indústria de transformação beneficiou-se da excelência na produção de matéria-prima.

Nos anos 70, as luvas já despontavam como o produto manufaturado baseado em látex mais significante, e passaram a atrair investimentos estrangeiros. A produção de artefatos de látex recebeu um grande impulso e incentivo com o lançamento do IMP1 (1986/1995). Durante esse período, a Malásia consolidou-se como o maior consumidor mundial de látex natural, e líder no fornecimento de luvas médicas. 


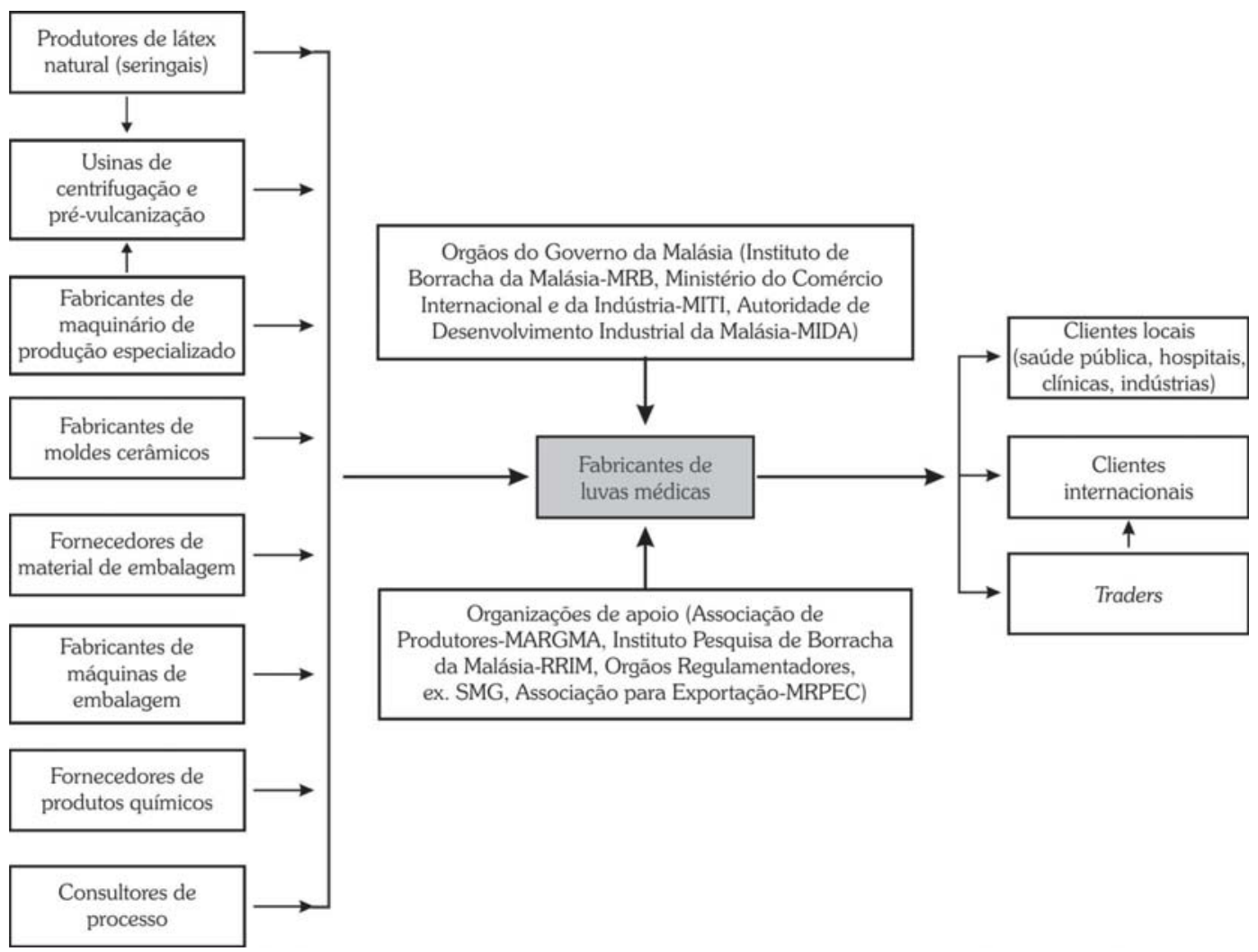

Figura 1: O Aglomerado de Luvas Médicas da Malásia.

Fonte: Elaborada pelos autores.

Os fabricantes de luvas médicas estão no centro do aglomerado. Constituem um conjunto de empresas com características bastante diversificadas. Em 2004, existiam 80 diferentes empresas estabelecidas na Malásia. Entre essas companhias estão empresas multinacionais, com fábricas em vários continentes, grandes grupos locais, com centenas de linhas de produção distribuídas em diversas unidades fabris na Malásia, e até pequenas empresas familiares. A grande maioria delas produz luvas cirúrgicas e de exame. Poucas produzem apenas luvas de uso doméstico ou completam a linha com outros artefatos, como balões ou preservativos.

Existem pelo menos 18 fabricantes de insumos químicos especializados para indústria de luvas. Quantos aos moldes cerâmicos, há cinco fabricantes produzindo as mais diversas formas de porcelana para confecção de luvas. 
Há sete empresas fabricando equipamentos especializados para produção de luvas. Ao todo, a indústria manufatureira de borracha na Malásia empregava em 2004 cerca de 67.000 trabalhadores. Estima-se que $60 \%$, ou 40.200 deles, atuavam diretamente nas indústrias fabricantes de luvas (Departamento de Estatística, Governo da Malásia - 2004).

\subsection{Instituições Especializadas}

O Malaysian Rubber Board (MRB) foi estabelecido em 1998, como resultado da fusão dos três maiores institutos que trabalhavam no desenvolvimento da indústria de borracha local: Malaysian Rubber Researsh and Development Board, Rubber Researsh Institute of Malaysia (RRIM) e Malaysian Rubber Exchange and Licensing Board. O MBR é uma agência governamental vinculada ao Ministério das Indústrias Agrícola e Commodities. Sua primeira grande missão foi encontrar uma solução economicamente viável para eliminação das proteínas alergênicas do látex. As mudanças nos processos de produção implementadas permitiram atingir níveis seguros de proteínas alergênicas nas luvas.

Malaysian Rubber Export Promotion Council (MREPC) promove no exterior os artigos de borracha e látex, especialmente as luvas de exame. Ainda como parte da estratégia de promoção das luvas médicas da Malásia e esclarecimento quanto à questão da alergia ao látex, o MRPEC abriu um escritório técnico-comercial em Washington - DC (EUA). Entre outras atividades, destacam-se os seminários, encontros e workshops. Os EUA, apesar das suas restrições ao látex natural, absorvem atualmente $42 \%$ das exportações de luvas da Malásia.

A Malaysian Rubber Glove Manufacturers Association (MARGMA), fundada em 1990, é a associação de fabricantes que reúne 52 membros efetivos e 80 membros associados (fornecedores e indústria de apoio). É responsável pela realização de Conferências e Exibições Internacionais, que atraem para a Malásia agentes do setor de todo o mundo. Mantém intercâmbio com associações análogas da Tailândia e Indonésia e trabalha fortemente na padronização dos produtos quanto a dimensões, critérios de testes, propriedades físicas e de resistência mecânica. 


\subsection{Os Fatores de Produção (Insumos)}

Recursos naturais: o setor das indústrias de produtos de borracha, particularmente o de luvas, teve um crescimento tão espetacular que, mesmo a Malásia sendo o terceiro maior produtor de látex natural, tornou-se importadora de matéria-prima. O desenvolvimento da qualidade deste recurso e a especialização na sua produção para usos em tais artefatos beneficiam a competitividade do setor.

Recursos humanos: viu-se que a Malásia possui mão de obra especializada e instruída. Além disso, há o traço cultural que contribui para a atratividade de indústrias de mão de obra intensiva.

Recursos de capital: o governo da Malásia fez a escolha política de atrair investimentos externos para industrializar o país. Os planos de desenvolvimento industrial contemplaram incentivos fiscais, incentivos à exportação $e$ doações a institutos de pesquisa. O setor expandiu-se rapidamente, a taxas médias de 33\% a.a. durante o IMP1 (1986/1995).

Infraestrutura física: a infraestrutura de transportes, rodovias, ferrovias, aeroportos e portos, de armazéns, de energia elétrica, de gás canalizado e de água e esgoto é bem desenvolvida na Malásia. O país beneficia-se do legado da colonização inglesa e do fato de ser uma pequena península, com menores distâncias geográficas a serem vencidas.

Infraestrutura administrativa do governo e empresas: do ponto de vista governamental, toda rede administrativa e que pode impactar no custo dos negócios e transações está informatizada e orientada para máxima eficiência. As empresas também buscam uma estrutura enxuta, com foco na qualidade e produtividade.

Infraestrutura de informação: as várias instituições de pesquisa e apoio do aglomerado e as agências estatais, disponibilizam amplamente estatítiscas, normatização, relatórios e projeções. Os meios usados são internet, boletins setoriais, relatórios gratuitos ou pagos, publicações específicas e guias de empresas. O fato de tantas empresas concorrentes concentrarem-se na localidade proporciona intercâmbio tecnológico e mercadológico, estruturado justamente nesses organismos.

Infraestrutura científica e tecnológica: o papel do MRB tem um peso decisivo. É fruto de uma tradição de mais de 78 anos na pesquisa e desenvolvimento da indústria de borracha. O setor de luvas possui vários programas específicos junto ao RMB, destacando-se o SMG (Standard Malaysian 
Glove). É um fator importante para a continuidade da sua liderança mundial em termos tecnológicos.

Todos estes insumos do aglomerado têm qualidade e são competitivos. Ressalte-se que os recursos naturais, humanos, informação e científico/ tecnológicos são extremamente especializados.

\subsection{Condições da Demanda}

A teoria identifica como fonte de vantagem competitiva a existência de clientes locais sofisticados e exigentes, cujas necessidades antecipem as que surgirão em outros lugares. Como a produção de luvas na Malásia visa eminentemente a exportação, o conceito tem que ser adaptado de alguma forma. Então, parece razoável que seja analisado nas suas especificidades o maior mercado consumidor de luvas, os EUA.

Esse mercado é extremamente exigente dado seu alto poder aquisitivo, seu alto nível tecnológico, notadamente o de saúde. A legislação para produtos médicos é rigorosa. Some-se a isso a problemática da alergia ao látex natural e a série de restrições e imposições que daí decorreram. O mercado norte-americano ditou e antecipou uma preocupação crescente de saúde pública. A reação positiva dos fornecedores malaios, sendo ainda mais rigorosos nos seus padrões, os fez liderar, uma vez mais, todo o desenvolvimento de luvas médicas com melhores propriedades de uso seguro. Resultado disso é que o aglomerado todo se beneficiou do salto qualitativo e da diversificação de produtos decorrentes dos avanços.

\subsection{Setores Correlatos e de Apoio}

Fornecedores: o parque de fornecedores local é internacionalmente competitivo e capaz. Os produtores de látex exportam para o mundo todo; os fabricantes de maquinário exportam para a Ásia e têm buscado novos mercados. Os ceramistas, produtores de moldes de porcelana, também têm na Malásia sua base de exportação.

Setores correlatos: dentre os setores correlatos mais semelhantes, ou seja, que fabricam artefatos de látex natural por processo de imersão, destacam-se o de cateteres, no qual a Malásia também é líder mundial, e o de preservativos. Esses setores correlatos utilizam vários insumos em comum, 
Luís G. Mazzaro • Fábio L. Oliva - Celso C. de H. e Grisi • Hubert Drouvot • Sérgio Crispim • Marcos A. Gaspar

tais como látex natural e produtos químicos. Os fabricantes de maquinários especializados são compartilhados, assim como os consultores de processo.

\subsection{Contexto para a Estratégia e Rivalidade das Empresas}

Embora haja colaboração nas associações de produtores e exportadores, não há relatos de cartelização, acordos de preços ou outras práticas lesivas à concorrência. Nesse setor, com mais de 80 fabricantes, empresas de diversos portes e origens, a competição tende a ser perfeita. As políticas de desenvolvimento industrial pautaram-se pelos esforços na atração de investimentos externos e ênfase nas exportações do aglomerado. $\mathrm{O}$ incentivo às exportações está presente nos atos regulatórios e legislação local.

\subsection{Os Fatores e a Produtividade no Aglomerado}

O Estado da Malásia criou, em 1962, um programa conjunto com as Nações Unidas, através da Organização Mundial do Trabalho (OIT): o Centro Nacional de Produtividade (NPC). O NPC atua na Pesquisa em áreas estratégicas de:

a) Qualidade e Produtividade para aumento da Competitividade;

b) Promoção do desenvolvimento de recursos humanos, construindo uma sociedade baseada no conhecimento;

c) Promoção de excelência organizacional e das melhores práticas para melhoria da produtividade e competitividade;

d)Disponibilizar dados e informações abrangentes sobre a produtividade; $e$

e) Aplicação de Tecnologia de Informação e Comunicação para melhoramento da produtividade e Intercâmbio com outras instituições de Qualidade e Produtividade Internacionais e Locais.

Considerando o setor manufatureiro de produtos de borracha, no período de 1993 a 1999, a produção total por funcionário aumentou 55,1\%, ou $6,5 \%$ a.a. o Valor agregado por funcionário; $81,1 \%$, ou $8,9 \%$ a.a. o Valor 
agregado por Ativo Fixo; 37.2\%, ou 4.6\% a.a. (NPC, 2000). O crescimento da produtividade é expressivo, especialmente por tratar-se de indústrias com mão de obra intensiva. Sabe-se que o peso dos fabricantes de luvas é $65 \%$ do valor agregado e $75 \%$ da mão de obra, assim sendo, verifica-se a expressividade do aumento da produtividade no setor.

Porter (1999) descreve certas características que conferem aos aglomerados influência positiva no crescimento da produtividade. No caso estudado podemos reconhecê-las:

Acesso a insumos e à pessoal especializado: observa-se que houve um fenômeno de especialização de empresas fornecedoras de maquinário e moldes de cerâmica, por exemplo. Tais fabricantes têm soluções sob medida para a indústria manufatureira e trabalha em parceria no aperfeiçoamento da produtividade dos equipamentos. A mão de obra especializada, formada durante anos nas empresas produtoras de luvas, espalhou-se pelo aglomerado, contribuindo para que a cultura de produção de luvas fosse levada aos subfornecedores que surgiam.

Acesso à informação: os subfornecedores têm agido no sentido de disseminar através do aglomerado as melhores práticas desenvolvidas pelos fabricantes de luvas. Percebe-se que há uma constante evolução na concepção e execução dos principais equipamentos de produção, e que o conceito dominante de aumento de escala e melhora na remoção de proteínas, por exemplo, passa a ser adotado por todo o setor.

Complementaridades: os fabricantes, através da MRPEC e da MARGMA, efetivam ações conjuntas para desenvolver mercados, promover seus produtos e garantir um padrão de qualidade internacionalmente aceito.

Acesso a instituições e a bens públicos: a participação do MRB, órgão público de pesquisa e desenvolvimento de tecnologia de borracha, tem sido fundamental para o aumento da produtividade agrícola e industrial do setor.

Incentivos e mensuração do desempenho: o Estado mantém disponíveis na internet, seja através do Departamento de Estatísticas, MRB ou NPC, um conjunto amplo de informações sobre o desempenho setorial. Além dessas informações econômicas, há também extenso material técnico e normativo para a indústria de luvas.

Ao analisar a condição dos fatores considerados como positivos para crescimento da produtividade, portanto fontes de vantagem competitiva, notase que estão presentes e são todos coerentes com a Teoria da Competitividade. 


\section{Considerações Finais}

O objetivo deste trabalho foi estudar o desenvolvimento da competitividade do setor de Luvas Médicas da Malásia. Para tal, com base nas evidências iniciais e na bibliografia consultada, partimos do pressuposto que o setor é um aglomerado e que daí poderiam derivar fontes de competitividade internacional. Ao comparar os dados encontrados no aglomerado com as fontes de competitividade previstas na teoria, nota-se a forte correlação.

No aglomerado, a condição dos insumos, a condição da demanda, os setores correlatos e de apoio e as estratégias e rivalidade das empresas influenciam positivamente na competitividade, proporcionado um desenvolvimento constante do setor.

O papel do governo é marcante, compreende a definição de políticas de industrialização, a atração de capitais estrangeiros, a promoção das exportações e a organização das instituições de apoio à pesquisa e desenvolvimento. $\mathrm{O}$ foco das ações do Estado tem sido o aumento da produtividade das empresas. Essas práticas são alinhadas com a teoria dos aglomerados. Os planos IMP1 e IMP2 deram impulso ao crescimento do setor. No IMP2 é expressa claramente a adoção da visão de aglomerados industriais para desenvolvimento da competitividade econômica.

A política industrial é coerente com a teoria da competitividade, pois enfatiza a maior eficiência e integração entre empresas, na busca da crescente produtividade. Não se detectaram no aglomerado de luvas médicas, ações no sentido de distorcer a concorrência ou promover a concentração de empresas. Quanto às instituições de apoio, há as governamentais, fundamentalmente ocupadas na pesquisa e desenvolvimento, $e$ as associações de fabricantes exportadores, que têm agido com foco na normatização do produto $e$ em marketing internacional. 


\title{
The competitiveness in the clusters of southeastern asian rubber industry
}

\begin{abstract}
The objective of this paper is to study the competitiveness of the manufacturing sector of rubber products of Malaysia, through the analysis of the medical gloves industry. The joint action between the productive sector and the State privileged the attraction of foreign investments, the focus in the exportations, the search of the competitiveness through the productivity and the best use of the resources. These practical are coherent with the clusters theory, therefore they exactly emphasize the supported growth of the productivity and the competitiveness, and not the temporary advantages or firms concentration. The performance of the specialized institutions of technological research and of the associations of the manufacturers has been expressive, either for standardization purposes, improvement of quality and product promotion in the foreign. The case study offers a counterpoint for evaluation of the strategies for industrial development in Brazil.
\end{abstract}

Key-words: Clusters. Competitiveness. Rubber industry.

\section{REFERÊNCIAS}

CONTADOR, J. C. Armas da competição. Revista de Administração, São Paulo, v. 30, n. 2, p. 50-64, abr./jun. 1995.

MALÁSIA. Department of Statistics. Disponível em: <http:// www.statistics.gov.my>. Acesso em: 10 abr. 2004.

ELIOT, J.; BICKERSETH J. Malaysia handbook. Bath: Footprint Handbooks, 2002.

IMD - INTERNATIONAL INSTITUTE FOR MANAGEMENT DEVELOPMENT. World Competitiveness Yearbook - 2004. Lausanne. Disponível em: $<$ http://www.imd.ch>. Acesso em: 26 abr. 2005. 
Luís G. Mazzaro • Fábio L. Oliva - Celso C. de H. e Grisi • Hubert Drouvot • Sérgio Crispim • Marcos A. Gaspar

MARGMA - MALAYSIAN RUBBER GLOVE MANUFACTURERS

ASSOCIATION. Kuala Lumpur. Disponível em: < http://

www.margma.com.my>. Acesso em: 26 abr. 2005.

MARTIN, R.; SUNLEY, P. Desconstructing clusters: Chaotic concept or policy

panacea? In: Regional Studies Association Conference on

Regionalising the Knowledge Economy. London. 2001.

MBR - MALAYSIAN RUBBER BOARD. Kuala Lumpur. Disponível em: < http:// www.lgm.gov.my >. Acesso em: 24 abr. 2005.

MIDA - MALAYSIAN INDUSTRIAL DEVELOPMENT AUTHORITY. Kuala

Lumpur. Disponível em: <http://www.mida.gov.my>. Acesso em: 26 abr. 2005.

MINISTÉRIO DAS FINANÇAS, GOVERNO DA MALÁSIA. Relatório econômico 2004/2005. New Straits Times, Kuala Lumpur: New Straits Times, 11 set. 2004.

MITI - MINISTRY OF INTERNATIONAL TRADE AND INDUSTRY. Disponível em: <http://www.miti.gov.my >. Acesso em: 18 abr. 2005.

MREPC - THE MALAYSIAN RUBBER EXPORT PROMOTION COUNCIL. Disponível em: <http://www.mrepc.com>. Acesso em: 12 abr. 2005.

NPC - NATIONAL PRODUCTIVITY CORPORATION. Productivity Report 2000. Disponível em: <http://dominoapp.npc.org.my>. Acesso em: 22 abr. 2005.

PORTER, M. E. A vantagem competitiva das nações. Rio de Janeiro: Campus, 1990.

PORTER, M. E. Competição = On competition: estratégias competitivas essenciais. Rio de Janeiro: Elsevier, 1999.

SÖLVELL, Ö.; LINDQVIST, G.; KETELS, C. The Cluster Initiative Greenbook Stockholm: Ivory Tower 2003. Disponível em: <http:// www.cluster-research.org >. Acesso em: 12 abr. 2005

YIN, R. K. Estudo de caso: planejamento e métodos. Porto Alegre: Bookman, 2003. 